\title{
Plasma Exchange in Secondary Progressive Multiple Sclerosis: Twenty-Five Year Follow-Up Study
}

Bhupendra O Khatri ${ }^{1^{*}}$, Sergey Tarima ${ }^{2}$, Michael P McQuillen ${ }^{3}$, John Kramer ${ }^{1}$, Mary Dukic ${ }^{1}$ and Cynthia Bellanger ${ }^{4}$

${ }^{1}$ Center for Neurological Disorders, Wheaton Franciscan Health Care, Milwaukee, USA

${ }^{2}$ Medical College of Wisconsin, Milwaukee, USA

${ }^{3}$ Stanford University School of Medicine, USA

${ }^{4}$ Aurora St. Luke's Medical Center, USA

"Corresponding author: Dr. Bhupendra Khatri, Wheaton Franciscan Healthcare, Center for Neurological Disorders, 3237 S. 16th Street, Milwaukee, WI 53215, USA, Tel: 414-769-4040; Fax: 414-769-4041; E-mail: bokhatri@aol.com

Received date: Mar 18, 2014, Accepted date: Apr 24, 2014, Published date: Apr 28, 2014

Copyright: @ 2014 Khatri B, et al. This is an open-access article distributed under the terms of the Creative Commons Attribution License, which permits unrestricted use, distribution, and reproduction in any medium, provided the original author and source are credited.

\begin{abstract}
Secondary Progressive multiple sclerosis (SPMS) is a common form of MS with few approved and effective therapies. Previous studies of therapeutic plasma exchange (PLEX) in SPMS have reported mixed results. The purpose of this study was to evaluate long-term efficacy and safety of PLEX in SPMS. We retrospectively analyzed 25 years of PLEX therapy in SPMS to identify improvements in disease progression and disability as well as potential predictors of therapeutic success. Using 271 patients, we show a significant improvement in Expanded Disability Status Scale (EDSS) lasting for at least three years following a course of PLEX. Furthermore, disability remained significantly improved or stabilized for seven years post-PLEX. Patients with continued and measureable disability worsening in the previous three years are more apt to improve with PLEX. A small number of patients $(\mathrm{N}=42)$ for whom PLEX was considered but denied by their insurance carriers, and who therefore received other treatments, were also followed over the 25 year period. Progression of disability in this group was significantly worse when compared with PLEX group. No major problems occurred during 8709 PLEX procedures. Peripheral vascular access (venous or arterial) was utilized to avoid complications related to central line placement.
\end{abstract}

Because of the paucity of beneficial therapeutic interventions in SPMS and the relative safety and efficacy of long-term PLEX, this therapy should be considered in this form of MS.

Keywords: PLEX; Plasmapheresis; Retrospective analysis; Secondary progressive multiple sclerosis

\section{Introduction}

SPMS is the most prevalent form of the disease. Approximately $80 \%$ of patients are initially diagnosed with relapsing-remitting MS (RRMS), and 66 [1] to 80\% [2] of these patient convert to SPMS. Safe, effective, long-term therapy is lacking for this form of MS [3,4].

Therapeutic plasma exchange (PLEX, apheresis or plasmapheresis) therapy is a process in which the fluid part of the blood called plasma, is separated and removed from red blood cells, white blood cells, and platelets. These blood cells are returned to the patient undergoing treatment. At the same time, the plasma is discarded and replaced with other fluids. PLEX is an accepted intervention for many autoimmune neurological conditions [5] including a severe, corticosteroid-resistant MS exacerbation [6]. While the mechanism of action of PLEX is likely disparate and dependent on specific pathogenesis, the broad utility of this therapy is clear [5]. Preliminary studies of PLEX in SPMS [7-12] led way to three double-blind randomized controlled clinical trials [13-15]. Pilot studies of PLEX in chronic progressive MS (CPMS) patients taking azathioprine and prednisone $[7,12]$ demonstrated modest, but less well-sustained, improvement. A larger study in which a prolonged apheresis protocol was used in patients taking cyclophosphamide and prednisone [10], showed significant and wellsustained improvement in 28 of 45 patients and stabilization of the course in the rest. Clinical improvement was associated with improvement in evoked potential studies and in suppressor cell functional activity in those patients. These observations led to a randomized controlled trial of plasma removal versus sham apheresis in patients treated with immunosuppressive drug therapy (ISDT) [13]. Use of ISDT alone (sham apheresis group, $\mathrm{N}=29$ ) was associated with a small improvement (one or more steps in EDSS; mean change of 1.5) in 8 and stabilization of MS in 18 patients, with this status sustained in 23 patients at 11 months follow-up after entry. In contrast, 14 of 26 patients who received true apheresis improved (mean change of 2.6) and 11 more were stable with these changes sustained in 23 of 26 patients at follow-up. These differences overall, between true and sham apheresis groups, were significant $(\mathrm{p}<0.007)$. An uncontrolled study, using an identical protocol in 33 CPMS patients [16], demonstrated significant $(\mathrm{p}<0.001)$ clinical improvement as measured by EDSS.

Three double-blind, randomized controlled studies of PLEX and ISDT in CPMS have been reported [13-15]. A major difference in methods between the first two was the use of weekly PLEX for 20 weeks, along with low-dose oral cyclophosphamide, prednisone and human IgG in one study [13], whereas only eight PLEX were given over 3 weeks, along with azathioprine and prednisone, in the other [14]. Clinical improvement in PLEX treated group was noted in both studies. However, the degree of improvement at completion and during follow-up was significantly better in the study that used a more protracted course of PLEX. This is not surprising, especially when dealing with a form of disease that is chronic and progressive. In fact, 
objective clinical improvement in the PLEX treated group in the first study [13] was not noted by the blinded observers until after ten PLEX on average. A controlled clinical trial [13], retrospective analysis [17], and other data [18] demonstrated PLEX as an appropriate therapy for subgroups of progressive MS patients [13]. The Canadian Cooperative MS Study Group [15] evaluated the efficacy of PLEX in chronic progressive MS and found PLEX in conjunction with immunosuppressive drug therapy to be of no benefit. Except for some minor differences [19], the protocol was similar to the one we used [13]. The frequent and uncontrolled use of corticosteroids in the Canadian study (21/56 in the placebo group with only $8 / 56$ in the plasmapheresis group ) is datum worthy of comment in their final analysis, especially since the authors of the Canadian study acknowledged that PLEX delayed the time to treatment failure significantly $(p=0.005)$ [20] Finally, a meta-analysis of clinical data determined that PLEX is an effective therapy in SPMS [21]. These disparate results led the American Academy of Neurology to withhold endorsement of PLEX for SPMS [6].

In light of this debate, we analyzed our 25-year experience with PLEX in SPMS. We found that a subset of patients who are most vulnerable to deteriorate rapidly, as indicated by an Extended Disability Status Scale (EDSS) of 4 or more, responded well to PLEX. Additionally, patients with measurable disability progression within the three years prior to PLEX can be used to identify potential responders to this therapy.

\section{Materials and Methods}

\section{Subjects}

We considered all patients with clinically-definite MS and a secondary progressive course as manifest by continuous worsening on serial neurologic examination for at least 12 months. Even though PLEX is not a guideline-recommended therapy for this form of the disease [6], some insurance carriers approved the intervention when provided with documented worsening and evidence of steroid refractoriness. Only patients whose insurance companies approved the procedure received PLEX. Patients who were considered for PLEX but were denied insurance coverage of PLEX served as control comparators. Patients with relapsing-remitting MS (RRMS), or those patients in the midst of an exacerbation, were not included in this analysis. Written consent was obtained from all patients included in the analysis.

\section{PLEX therapy}

For patients receiving PLEX, therapy was initiated once weekly for 10 weeks and then at gradually-increasing treatment intervals, as dictated by the patient's insurance carrier and clinical response. In some patients these treatment paradigms eventually rendered PLEX as a maintenance therapy once every four to six weeks. Because of the dependence of PLEX treatment upon often-interrupted insurance coverage, PLEX therapy was frequently fragmented. Forty-two steroidrefractory progressive MS patients never received PLEX during the treatment window reviewed and thus served as our Non-PLEX control group.

\section{PLEX procedure}

All procedures were performed using a continuous flow apheresis machine. One plasma volume was exchanged during each procedure.
Replacement fluid consisted of 5\% albumin and normal saline $(3: 1)$. Calcium gluconate $(3 \mathrm{ml}$ of $10 \%$ ) was added to each $250 \mathrm{ml}$ of replacement fluid. Citrate Dextrose Solution (ACD-A) was used for anticoagulation. Peripheral venous access was attempted in all patients using a 16-gauge angiocatheter. For patients with poor venous access, temporary radial or brachial artery catheterization [22] was used for blood removal, with a peripheral venous access line (standard 18gauge angiocatheter) to return blood cells and replacement fluids. Indwelling central lines were not used on these patients due to potential complications [23]. Vital signs were monitored every 30 minutes during the procedure. A total of 8709 PLEX procedures were performed without any major side effects, and 2654 radial or brachial arterial lines were temporarily placed in patients with poor vascular access without any serious complications.

\section{Neurological examination}

A routine neurological evaluation was performed prior to each exchange and then at yearly follow-ups. EDSS was used to measure the disability level. For the purposes of this study, any decline in EDSS from baseline ( $>0.5$ ) were classified as "improved", those who did not change in disability were classified as "stable" and those who worsened on EDSS (>0.5) compared to their baseline were classified as "worse".

\section{Statistical methods}

EDSS is not a linear scale [24], and a one-step change lower EDSS scores (e.g. from 3 to 4 ) represents a less clinically significant change from a similar magnitude change (e.g. from 6 to 7 ) at the higher end of the scale. We used regression models to control for the previous EDSS values and to evaluate the effects of other significant confounders (age, gender, duration of disease, etc.) when analyzing the effect of PLEX treatment.

The annual changes in the EDSS were analyzed with mixed linear models, where random effect was used to account for possible dependence between person-specific EDSS assessments [25].

Subsequent to the mixed linear model analysis, we analyzed EDSS change as a binary function (progression versus no progression) as an indicator of annual disease progression. This random effect logistic regression model was used to determine the clinical significance of PLEX on MS progression [26]. We also compared the disability progression in the PLEX group to that of the No-PLEX control group.

In total, we analyzed 5,723 person-years from 323 individuals. Among the 323 patients, 52 never had PLEX (No-PLEX group). There was no adequate follow up on ten of these patients. The person-years of 42 patients therefore contributed to the control group. Two hundred seventy-one patients received PLEX; those patients' personyears contributed to PLEX group.

Since reaching EDSS 4 signifies a fundamental pathologic change in disability [27], we also examined the effect of PLEX in patients with EDSS below or equal to 4 and above 4.5 .

\section{Results}

\section{Baseline characteristics}

Of the 323 patients for whom PLEX was recommended, 271 received this therapy. Insurance carriers for remaining 52 (10 patients for which we did not have enough data for comparisons) denied this 
Citation: Khatri BO, Tarima S, McQuillen MP, Kramer J, Dukic M et al. (2014) Plasma Exchange in Secondary Progressive Multiple Sclerosis:

Page 3 of 7

therapy and they served as a Non-PLEX control group. The baseline characteristics of these patients are summarized in Table 1. In our dataset we had 5723 person-years from 323 participants. We kept only those person-years where we could assess yearly change between two consecutive years.

\begin{tabular}{|c|c|c|c|}
\hline Characteristic & No-PLEX & PLEX & $P$ value \\
\hline $\mathrm{N}$ & 42 & 271 & \\
\hline Age & \multirow{2}{*}{$47.5 \pm 9.3$} & \multirow{2}{*}{$41.5 \pm 10.6$} & \multirow{2}{*}{$<0.001$} \\
\hline$($ mean $\pm S D)$ & & & \\
\hline Female (\%) & 72.7 & 73.8 & 0.855 \\
\hline $\begin{array}{l}\text { Duration of Disease } \\
\text { (years, mean } \pm S D \text { ) }\end{array}$ & $11.3 \pm 8.0$ & $8.8 \pm 7.7$ & 0.048 \\
\hline EDSS & \multirow{2}{*}{$5.9 \pm 1.7$} & \multirow{2}{*}{$6.7 \pm 1.32$} & \multirow{2}{*}{$<0.001$} \\
\hline (Mean \pm SD) & & & \\
\hline Age of Onset & \multirow{2}{*}{$36.3 \pm 8.6$} & \multirow{2}{*}{$32.9 \pm 9.6$} & \multirow{2}{*}{0.026} \\
\hline (years, mean $\pm S D$ ) & & & \\
\hline
\end{tabular}

Table 1: Baseline characteristics of PLEX and No-PLEX patients.

\section{Sustained Long-term patient response to PLEX}

We found a significant $(\mathrm{p}<0.0001)$ and sustained improvement in disability and during the first 3 years for patients treated with PLEX (Table 2).

\begin{tabular}{|c|c|c|c|c|}
\hline Count or mean (SE) & Improved & Stable & Worse & $\begin{array}{l}\text { P-value } \\
\text { (Improved vs } \\
\text { Stable) }\end{array}$ \\
\hline $\mathrm{N}$ & 174 & 95 & 2 & \\
\hline \multicolumn{5}{|l|}{ Sex } \\
\hline $\mathrm{F}$ & 127 & 72 & 1 & \\
\hline M & 47 & 23 & 1 & \\
\hline Age & $40.4(0.8)$ & $\begin{array}{l}43.5 \\
(1.1)\end{array}$ & $42.0(7.4)$ & 0.0223 \\
\hline Age Onset & $32.3(0.7)$ & $\begin{array}{l}33.9 \\
(1.0)\end{array}$ & $31.0(6.8)$ & 0.1990 \\
\hline Duration & $8.4(0.6)$ & $\begin{array}{l}9.5 \\
(0.8)\end{array}$ & $11.0(5.5)$ & 0.2660 \\
\hline Pre EDSS & $6.7(0.1)$ & $\begin{array}{l}6.7 \\
(0.1)\end{array}$ & $4.8(0.9)$ & 0.8900 \\
\hline $\begin{array}{l}\text { One year EDSS } \\
\text { change }(\mathrm{N}=261)\end{array}$ & $0.9(0.1)$ & $\begin{array}{l}0.2 \\
(0.1)\end{array}$ & $-1.3(0.7)$ & $<0.0001$ \\
\hline $\begin{array}{l}\text { Two years EDSS } \\
\text { change }(\mathrm{N}=232)\end{array}$ & $1.4(0.1)$ & $\begin{array}{l}0.7 \\
(0.1)\end{array}$ & $-1.25(0.7)$ & $<0.0001$ \\
\hline $\begin{array}{l}\text { Three years EDSS } \\
\text { change }(\mathrm{N}=183)\end{array}$ & $1.8(0.1)$ & $\begin{array}{l}1.0 \\
(0.1)\end{array}$ & $-0.8(0.8)$ & $<0.0001$ \\
\hline
\end{tabular}

Table 2: Three-year treatment outcomes among 271 PLEX patients.

\section{Stable $=$ No change in EDSS}

Worse $=$ Any worsening on EDSS $(>0.5)$ compared to baseline

Clinical outcomes in 271 PLEX patients (how many improved, remained the same or became worse) over the three year follow-up is summarized in Table 3.

\begin{tabular}{|l|l|l|l|l|l|l|}
\hline & $\begin{array}{l}\text { N } \\
\text { (observed) }\end{array}$ & $\begin{array}{l}\text { Impr } \\
\text { oved }\end{array}$ & Same & Worse & $\begin{array}{l}\text { P-value } \\
\text { (Improv } \\
\text { ed vs. } \\
\text { Worse) }\end{array}$ & $\begin{array}{l}\text { P-value } \\
\text { (Improved + } \\
\text { Same } \\
\text { Worse) }\end{array}$ \\
\hline Post Tx & 271 & 174 & 95 & 2 & $<0.0001$ & $<0.0001$ \\
\hline $\begin{array}{l}1 \quad \text { year } \\
\text { post }\end{array}$ & 268 & 139 & 105 & 24 & $<0.0001$ & $<0.0001$ \\
\hline $\begin{array}{l}2 \quad \text { years } \\
\text { post }\end{array}$ & 264 & 121 & 93 & 50 & $<0.0001$ & $<0.0001$ \\
\hline $\begin{array}{l}3 \quad \text { years } \\
\text { post }\end{array}$ & 248 & 97 & 87 & 64 & 0.0114 & $<0.0001$ \\
\hline
\end{tabular}

Table 3: PLEX treatment outcomes among patients with data immediately before and after PLEX treatment.

The disability remained the same as when they had just started PLEX through years 5-7 and worsened thereafter (Table 4).

Of the 271 who received PLEX, 139 improved by one more points on EDSS ( $\mathrm{p}<0.0001$, improved vs. worse or improved vs. worse combined with those who remained stable.) These findings remained significantly sustained at 3 years after PLEX therapy; 105 remained stabilized and 24 worse at one year post PLEX.

\section{PLEX versus No PLEX groups}

We found a significant $\mathrm{p}<0.0001$ improvement in disability progression during the first year for patients treated with PLEX compared to the Non-PLEX group (Figure 1).

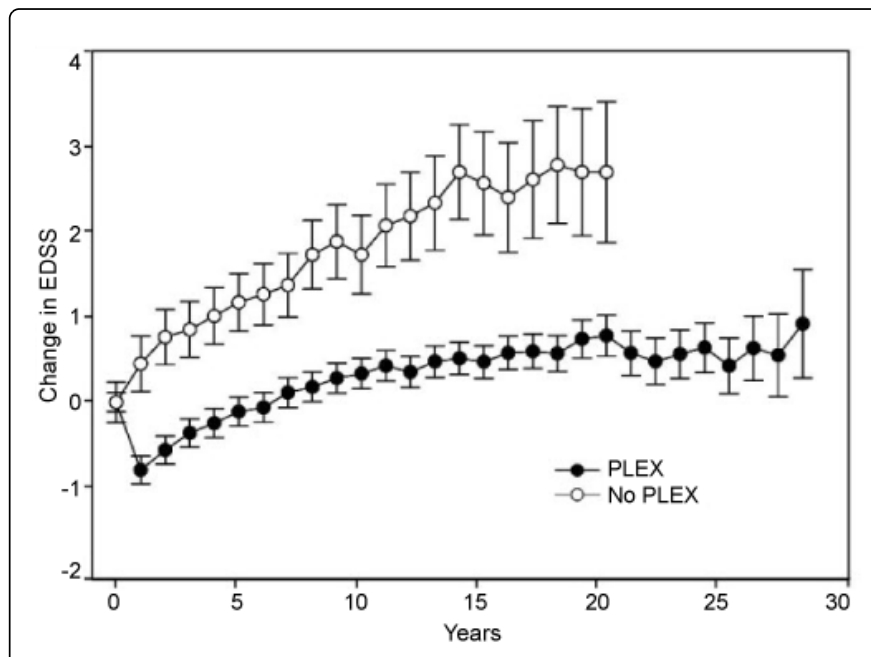

Figure 1: Over time, SPMS patients treated with PLEX incur less disability than control patients. 
Citation: Khatri BO, Tarima S, McQuillen MP, Kramer J, Dukic M et al. (2014) Plasma Exchange in Secondary Progressive Multiple Sclerosis: Twenty-Five Year Follow-Up Study. J Mult Scler 1: 102. doi:10.4172/jmso.1000102

Page 4 of 7

\begin{tabular}{|l|l|l|l|l|l|l|}
\hline & N (observed) & Improved & Same & Worse & $\begin{array}{l}\text { P-value (Improved vs. } \\
\text { Worse) }\end{array}$ & $\begin{array}{l}\text { P-value (Improved + Same vs. } \\
\text { Worse) }\end{array}$ \\
\hline 1 year post & 172 & 136 & 24 & 12 & $<0.0001$ & $<0.0001$ \\
\hline 2 years post & 169 & 119 & 28 & 22 & $<0.0001$ & $<0.0001$ \\
\hline 3 years post & 164 & 95 & 37 & 32 & $<0.0001$ & $<0.0001$ \\
\hline 4 years post & 155 & 79 & 32 & 44 & 0.0020 & $<0.0001$ \\
\hline 5 years post & 145 & 66 & 32 & 47 & 0.0900 & $<0.0001$ \\
\hline 6 years post & 137 & 61 & 32 & 44 & 0.1180 & $<0.0001$ \\
\hline 7 years post & 134 & 53 & 27 & 54 & 1.0000 & 0.0304 \\
\hline 8 years post & 133 & 46 & 29 & 58 & 0.2807 & 0.1651 \\
\hline 9 years post & 132 & 44 & 25 & 63 & 0.0814 & 0.6636 \\
\hline 10 years post & 130 & 43 & 22 & 65 & 0.0428 & 1 \\
\hline
\end{tabular}

Table 4: Ten-year follow up of 174 respondents (among 174, 172 had both pretreatment and 1st year assessments).

Patients were grouped as either having received PLEX (PLEX, black) or never having received PLEX (No PLEX, white). A comparison between these groups revealed a significant slowing of disability accumulation in the PLEX-treated group, where the PLEXtreated group showed a much smaller increase in EDSS score over the period of the study than did the No Plex group. Data shown represents average yearly change ( EDSS at beginning of study interval - EDSS at beginning of year) for PLEX and No PLEX groups since first PLEX treatment (for PLEX group) or first EDSS evaluation (for No PLEX group). Error bars represent point-wise confidence intervals and when not overlapping are significant at $\mathrm{P}=0.05$. PLEX group accrued disability more slowly than No PLEX group. This difference in rate of disability progression remained significant $(\mathrm{p}<0.0001)$ at each of the twenty years follow-up.

Additionally, patients in the PLEX group who accrued disability (as measured by EDSS) did so more slowly than did patients in the No PLEX (control) group. This difference in rate of disability progression remained significant $(\mathrm{p}<0.0001)$ at each of the twenty years follow-up. Gender, age and duration of disease had no significant effect.

\section{The effect of PLEX treatment on annual probabilities of EDSS progression}

We evaluated whether application of PLEX (or No PLEX) impacted the probability of progressing to a higher EDSS level during a calendar year (Table 5). To perform this analysis we measured and compared the probability of progression from the current EDSS to a higher EDSS level within one calendar year (Figure 2).

Patients were evaluated to determine if the use of PLEX influenced the odds of progressing to a higher EDSS level during a calendar year. Patient-years were used for this analysis; patients treated with PLEX during the calendar year were categorized as PLEX whereas patients without PLEX treatment were considered controls. When patients had an EDSS level greater than 4, they experienced a smaller magnitude change if treated with PLEX compared to controls $(\mathrm{P}<0.0001$; linear regression with random subject effect).

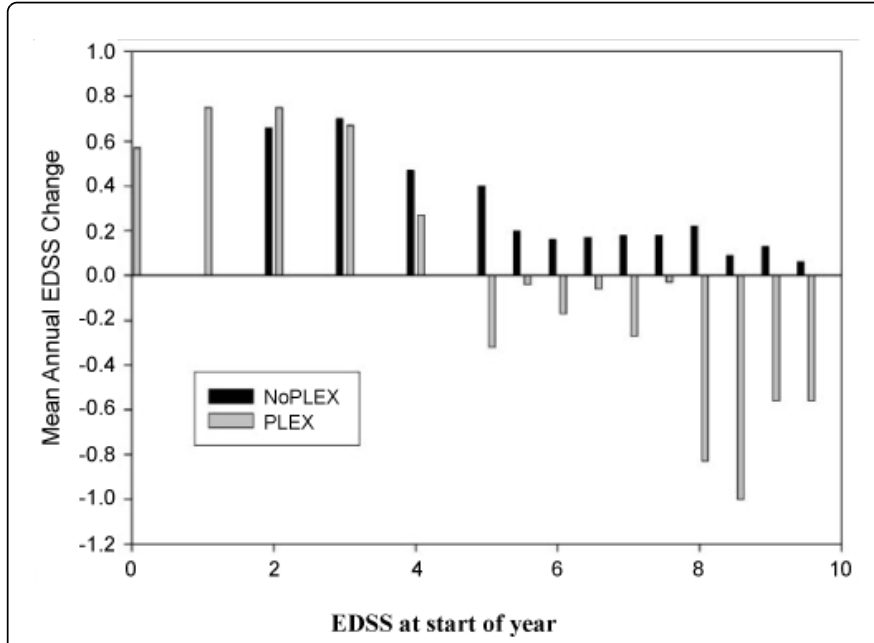

Figure 2: SPMS patients treated with PLEX experience a reduced increase in disability compared to controls.

Possible confounders (age, gender, age of onset, duration of disease, two-year progression in EDSS before the baseline year) were analyzed; none were significant. The results are summarized in Table 5. The probability of worsening on EDSS was significantly higher in No PLEX group than PLEX group $(\mathrm{p}<0.001)$ at all baseline disability.

The within-person dependence of EDSS scores was accounted for by a normal random subject effect added to a logistic regression model. Additionally, we tested for the effect of several confounding variables in our analyses: previous year EDSS as a categorical variable (0-6 vs. 6-6.5 vs. 7-9.5), gender, age, age at onset of MS, duration of disease, and the magnitude of disease progression in two previous years in EDSS scale. Among all of these potential confounders, only the category of a previous year EDSS was significant. Regression analysis revealed significant differences between the Non-PLEX and PLEX groups, regardless of subgroup. 


\begin{tabular}{|l|l|l|l|}
\hline \multirow{2}{*}{ EDSS } & No PLEX N=42 & PLEX & Significance \\
\cline { 2 - 4 } & (Males =12) & $\begin{array}{l}\text { N=268 (Males/ } \\
\text { Females71/197) }\end{array}$ & (P value) \\
\hline Group 1 & 0.9491 & 0.5052 & 0.0018 \\
\hline (EDSS $\leq 5.5)$ & \multirow{2}{*}{ Group 2 } & 0.2069 & 0.0005 \\
\hline (EDSS 6 - 6.5) & 0.3713 & 0.1159 & 0.001 \\
\hline Group 3 & 0.2536 & & \\
\hline (EDSS $\geq 7)$ & & &
\end{tabular}

Table 5: Annual probabilities of progression on EDSS.

A pathologic differentiation occurs in progressive MS at an EDSS of 4 [27]. We therefore elected to use a differentiation point of an EDSS of 4. Under this treatment paradigm, when the EDSS was greater than 4 , untreated patients had an odds of progression of 0.2689 while patients treated with PLEX had an odds of progression of 0.1425 $(\mathrm{P}<0.0001)$. For the patients with an EDSS of less than or equal to 4 in the control group (No PLEX), the odds of progression are 0.7820, while in the PLEX group the odds of progression are 0.6229 $(\mathrm{P}=0.3759)$. Thus, progressive MS patients with an EDSS greater than 4 are significantly less likely to progress to the next EDSS level of disability when treated with PLEX.

\section{The effect of PLEX treatment on the magnitude of annual EDSS change}

To further evaluate the response to PLEX treatment, we compared the mean change in EDSS over one calendar year between the PLEXtreated group and the control group (Figure 3).

Patients were evaluated to determine if the use of PLEX influenced their relative EDSS level between calendar years. Patient-years were used for this analysis; patients treated with PLEX during the calendar year were categorized as PLEX whereas patients without PLEX treatment were considered controls. When patients had an EDSS level greater than 4, they experienced a lower risk of progression to a higher EDSS level between calendar years if treated with PLEX compared to controls $(\mathrm{P}<0.0001$; logistic regression with random subject effect $)$.

Similar to the progression probabilities analysis above, no confounding variables were significant except for the previous year EDSS category. The random-effect model estimates that the mean EDSS annual change in the control group is 0.5121 if a previous year EDSS was less than 6, 0.1690 if the EDSS was 6 or 6.5 , and 0.1582 if the EDSS was 7 or higher. PLEX therapy consistently and significantly decreased these expected changes as summarized in Table 6.

An alternative stratification at an EDSS of 4 reveals a potential cut off EDSS for recommendation of PLEX treatment. Specifically, if the EDSS is 4 or less, the EDSS was expected to increase by 0.6100 in one year with PLEX treatment, and PLEX did not significantly change the disease prognosis $(\mathrm{p}=0.2765)$. With an EDSS above 4 , the yearly control group gain in EDSS was expected to be 0.1847. PLEX therapy decreased this value by $0.4491(\mathrm{P}<0.0001)$ and resulted in an expected improvement of 0.2644 units on the EDSS scale.

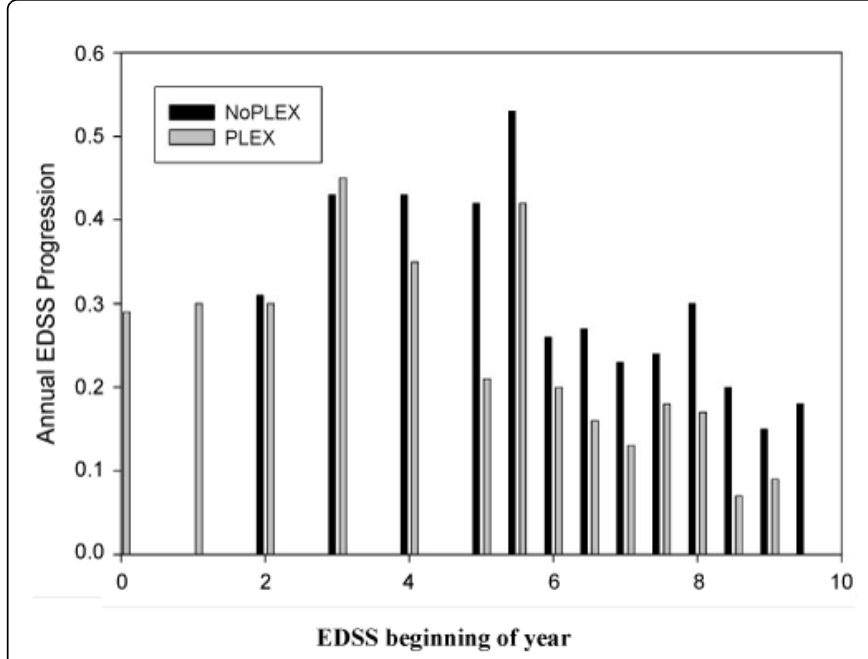

Figure 3: PLEX-treated SPMS patients have lower risk of progressing to higher EDSS level.

\begin{tabular}{|c|c|c|c|}
\hline EDSS & $\begin{array}{l}\text { No PLEX N=42 } \\
\text { (Males=71) }\end{array}$ & $\begin{array}{l}\text { PLEX } \\
\mathrm{N}=268 \quad \text { (Males } / \\
\text { Females=71/197) }\end{array}$ & $\begin{array}{l}\text { Significance } \\
\text { (P value) }\end{array}$ \\
\hline $\begin{array}{ll}\text { Group } & 1 \\
\text { EDSS } & \leq \\
5.5) & \end{array}$ & 0.5121 & -0.1541 & $<0.0001$ \\
\hline $\begin{array}{lll}\text { Group } & & 2 \\
\text { (EDSS } & 6 & - \\
6.5) & & \end{array}$ & 0.169 & -0.122 & $<0.0001$ \\
\hline $\begin{array}{l}\text { Group } \\
(\mathrm{EDSS} \geq 7)^{3}\end{array}$ & 0.1582 & -0.4357 & $<0.0001$ \\
\hline
\end{tabular}

Table 6: Magnitude of expected EDSS change in the next year.

\section{Safety}

A total of 8709 PLEX procedures were performed. There were no serious complications. Approximately $33 \%$ of patients at some point experienced symptomatic transient hypotension, readily corrected by rapid infusion of normal saline and $5 \%$ albumin solution and by placing a patient in Trendelenberg position. In some patients this was thought to be due to vaso-vagal disturbance. If hypotension occurred during subsequent procedures, the patient was pretreated with atropine $0.3 \mathrm{mg}$ IM. For most patients, the PLEX procedure was completed in two hours. For those in whom it took longer, the major complaint was excessive tiredness lasting for a day.

The duration of therapy was directly related to vascular flow. Vascular access was a problem in over $30 \%$ of patients; this was easily resolved with a simple technique [22] involving temporary radial (or brachial) arterial catheterization or femoral vein catheterization. 2654 such procedures were performed without significant morbidity.

\section{Discussion}

The goal of this study was to rigorously analyze the utility of PLEX in treating progressive MS in a real-world setting. Such analysis is important because of conflicting data in the literature regarding the 
use of PLEX in treating progressive MS. Blinded studies have been performed to address this issue and were either positive or equivocal [13-15]. Significantly, some of these studies included confounding therapeutics in both treatment and control groups [28]. Our retrospective, non-blinded and non-randomized study shows that PLEX therapy may be effective and may actually improve disability in progressive MS patients.

Specifically, PLEX therapy is most effective in patients with an EDSS of 4 or greater at a time when therapeutic intervention is most critically needed. This benefit was twofold, with initial improvement in PLEX-treated patients compared to Non-PLEX group and a decrease in subsequent rate of EDSS progression. Patients who are progressively acquiring more disability as assessed by an increasing EDSS in the three years prior, are more apt to benefit from PLEX therapy.

This is not a double-blind study, nor is it a well-planned prospective study. In addition, the treatment paradigm was highly influenced by the patient's insurance carriers. Further, since this study employs a retrospective analysis, there are clear limitations on the interpretations of these data. Importantly, such limitations do not alter the ultimate message of this study, which is that certain progressive MS patients experience a beneficial and long-lasting effect from PLEX therapy.

Because of the retrospective nature of this study, further work is required to examine the utility of PLEX in treating progressive MS. Specifically, this work should include MRI data and mechanism of action studies on PLEX in progressive and steroid-refractory MS. The data derived from these analyses would allow more narrowly-targeted therapeutics and guidelines for appropriate and meaningful application of PLEX.

There are notable advantages for using PLEX as a therapeutic intervention. PLEX is relatively safe, and the procedure is welltolerated [29] compared with other therapeutic agents such as mitoxantrone [30]. In this study alone, 22 patients received over 100 exchanges with no severe adverse events. Furthermore, these patients were unresponsive to steroids with few other therapeutic options. Because of the beneficial response we report with PLEX in progressive MS, we posit that a more aggressive PLEX intervention followed by a long-term maintenance plan could allow for less cumulative disability and less steroid use in these patients over time.

\section{Mechanism of Action}

The mechanism of action of PLEX is unknown and the pathophysiology of MS is complex. The role of B cells has been implicated, with the evidence of antibody-mediated tissue damage in $60 \%$ of MS lesions [31]. PLEX unequivocally removes circulating antibodies and this mechanism of action is likely to be an important factor in the response to PLEX [32]. It also improves the function and number of circulating suppressor T cells, which have been shown to be markedly low when the disease is active [10]. The removal of circulating interferon-inhibiting factor by PLEX and the subsequent increase in endogenous protection of IFN-a correlated with clinical improvement in another study [33]. What is clear is that further studies are required to understand how and why PLEX works in MS.

\section{Conclusions}

This retrospective comparator study supports earlier studies of the beneficial therapeutic effects of PLEX in the treatment of SPMS. While additional research is needed, it is also important to treat patients using the best potential therapeutic intervention, even if the data supporting these therapies remains empirical. The data presented herein is not definitive but certainly suggests significant beneficial effects of PLEX in patients with SPMS. So the question remains: why is PLEX not widely used in appropriate patients? There are multiple reasons, the foremost being that PLEX is not approved by a majority of insurance companies, despite convincing published data. In addition, vascular access is also a notable issue. While most centers use central lines for access, which can cause serious complications, this type of access is not necessary and in most patients antecubital access is a simpler alternative. For patients who do not have veins sufficient for antecubital access, we have been successfully using temporary radial artery catheterization. We find this procedure to be safe and effective, even when used repeatedly [22]. In addition, PLEX is not backed by any pharmaceutical companies and therefore no promotional or education support is available to market the procedure. While the cost of PLEX had been cited as an issue in the past, second-generation MS drugs are far more expensive and this may make PLEX an economical treatment choice. Lastly, an appropriate PLEX protocol needs to be followed for a given patient. Although this protocol varies from patient to patient, we utilize an induction protocol of six to ten treatments (weekly over 6-10 weeks), followed by a gradual taper as dictated by the clinical course. Most of these patients will require ongoing maintenance therapy ( once every 4-12 weeks).

MS is a lifelong disease. Once diagnosed patients usually live for another four to six decades. Long-term efficacy and safety are therefore very important. Our study is the longest time ever reported for patients on PLEX.

Because of the lack of alternative therapies for these forms of progressive MS and until additional trials are conducted, PLEX should be considered as a therapeutic option for SPMS.

\section{References}

1. Scalfari A, Neuhaus A, Daumer M, Ebers GC, Muraro PA (2011) Age and disability accumulation in multiple sclerosis. Neurology 77: 1246-1252.

2. Kremenchutzky M, Rice GP, Baskerville J, Wingerchuk DM, Ebers GC (2006) The natural history of multiple sclerosis: a geographically based study 9: observations on the progressive phase of the disease. Brain 129: 584-594.

3. Giovannoni G (2004) Management of secondary-progressive multiple sclerosis. CNS Drugs 18: 653-669.

4. Scott LJ, Figgitt DP (2004) Mitoxantrone: a review of its use in multiple sclerosis. CNS Drugs 18: 379-396.

5. Szczepiorkowski ZM, Winters JL, Bandarenko N, Kim HC, Linenberger ML et al. (2010) Guidelines on the use of therapeutic apheresis in clinical practice--evidence-based approach from the Apheresis Applications Committee of the American Society for Apheresis J Clin Apher 25: 83-177.

6. Cortese I, Chaudhry V, So YT, Cantor F, Cornblath DR, et al. (2011) Evidence-based guideline update: Plasmapheresis in neurologic disorders: report of the Therapeutics and Technology Assessment Subcommittee of the American Academy of Neurology. Neurology 76: 294-300.

7. Dau PC, Petajan JH, Johnson KP, Panitch HS, Bornstein MB (1980) Plasmapheresis in multiple sclerosis: preliminary findings. Neurology 30 : 1023-1028.

8. Hauser SL, Dawson DM, Lehrich JR, Beal MF, Kevy SV, et al. (1983) Intensive immunosuppression in progressive multiple sclerosis. A randomized, three-arm study of high-dose intravenous cyclophosphamide, plasma exchange, and ACTH. N Engl J Med 308: 173-180. 
Citation: Khatri BO, Tarima S, McQuillen MP, Kramer J, Dukic M et al. (2014) Plasma Exchange in Secondary Progressive Multiple Sclerosis: Twenty-Five Year Follow-Up Study. J Mult Scler 1: 102. doi:10.4172/jmso.1000102

Page 7 of 7

9. Höcker P, Stellamor V, Summer K, Mann M (1984) Plasma exchange (PE) and lymphocytapheresis (LCA) in multiple sclerosis (MS). Int J Artif Organs 7: 39-42.

10. Khatri BO, Koethe SM, McQuillen MP (1984) Plasmapheresis with immunosuppressive drug therapy in progressive multiple sclerosis. A pilot study. Arch Neurol 41: 734-738.

11. Tindall RS, Walker JE, Ehle AL, Near L, Rollins J, et al. (1982) Plasmapheresis in multiple sclerosis: prospective trial of pheresis and immunosuppression versus immunosuppression alone. Neurology 32: 739-743.

12. Weiner HL, Dawson DM (1980) Plasmapheresis in multiple sclerosis: preliminary study. Neurology 30: 1029-1033.

13. Khatri BO, McQuillen MP, Harrington GJ, Schmoll D, Hoffmann RG (1985) Chronic progressive multiple sclerosis: double-blind controlled study of plasmapheresis in patients taking immunosuppressive drugs. Neurology 35: 312-319.

14. Gordon PA, Carroll DJ, Etches WS, Jeffrey V, Marsh L, et al. (1985) A double-blind controlled pilot study of plasma exchange versus sham apheresis in chronic progressive multiple sclerosis. Can J Neurol Sci 12: 39-44.

15. The Canadian Copperative Multiple Sclerosis Study Group (1991) The Canadian cooperative trial of cyclophosphamide and plasma exchange in progressive multiple sclerosis. Lancet 337: 441-446.

16. Miller RG, Filler-Katz A, Kiprov DD (1985) More on plasmapheresis in chronic progressive MS. Neurology 35: 1261.

17. Khatri BO, McQuillen MP, Hoffmann RG, Harrington GJ, Schmoll D (1991) Plasma exchange in chronic progressive multiple sclerosis: a longterm study. Neurology 41: 409-414.

18. Weiner HL (1985) An assessment of plasma exchange in progressive multiple sclerosis. Neurology 35: 320-322.

19. Khatri BO, McQuillen MP, Hoffman RG (1991) Cyclophosphamide and plasma exchange in multiple sclerosis (letter). Lancet 337: 1033.

20. Noseworthy JH, Vandervoort MK, Penman M, Ebers G, Shumak K, et al (1991) Cyclophosphamide and plasma exchange in multiple sclerosis. Lancet 337: 1540-1541.

21. Vamvakas EC, Pineda AA, Weinshenker BG (1995) Meta-analysis of clinical studies of the efficacy of plasma exchange in the treatment of chronic progressive multiple sclerosis. J Clin Apher 10: 163-170.

22. Khatri BO (2003) Vascular access via temporary radial artery catheterization for therapeutic plasma exchange. J Clin Apher 18: 134.
23. Pikwer A, Åkeson J, Lindgren S (2012) Complications associated with peripheral or central routes for central venous cannulation. Anaesthesia 67: 65-71.

24. Hobart J, Freeman J, Thompson A (2000) Kurtzke scales revisited: the application of psychometric methods to clinical intuition. Brain 123 : 1027-1040.

25. McLean R, Sanders W, Stroup W (1991) A Unified Approach to Mixed Linear Models. The American Statistician 45: 54-64.

26. Breslow N, Clayton D (1993) Approximate Inference in Generalized Linear Mixed Models. Journal of the American Statistical Association 88: 9-25.

27. Leray E, Yaouanq J, Le Page E, Coustans M, Laplaud D, et al. (2010) Evidence for a two-stage disability progression in multiple sclerosis. Brain 133: 1900-1913.

28. Weiner HL, Dau PC, Khatri BO, Petajan JH, Birnbaum G, et al. (1989) Double-blind study of true vs. sham plasma exchange in patients treated with immunosuppression for acute attacks of multiple sclerosis. Neurology 39: 1143-1149.

29. Schaap-Fogler M, Schurr D, Schaap T, Leitersdorf E, Rund D (2009) Long-term plasma exchange for severe refractory hypertriglyceridemia: a decade of experience demonstrates safety and efficacy. J Clin Apher 24: 254-258.

30. Marriott JJ, Miyasaki JM, Gronseth G, O'Connor PW; Therapeutics and Technology Assessment Subcommittee of the American Academy of Neurology (2010) Evidence Report: The efficacy and safety of mitoxantrone (Novantrone) in the treatment of multiple sclerosis: Report of the Therapeutics and Technology Assessment Subcommittee of the American Academy of Neurology. Neurology 74: 1463-1470.

31. Disanto G, Morahan JM, Barnett MH, Giovannoni G, Ramagopalan SV (2012) The evidence for a role of B cells in multiple sclerosis. Neurology 78: 823-832.

32. Keegan M, König F, McClelland R, Brück W, Morales Y, et al. (2005) Relation between humoral pathological changes in multiple sclerosis and response to therapeutic plasma exchange. Lancet 366: 579-582.

33. Medenica RD, Mukerjee S, Huschart T, Corbitt W (1994) Interferon inhibitor factor predicting success of plasmapheresis in patients with multiple sclerosis. J Clin Apher 9: 216-221. 